\title{
Sustainable Development of Human Society in Terms of Natural Depleting Resources Preservation Using Natural Renewable Raw Materials in a Novel Ecological Material Production
}

\author{
Cătălina Mihaela Grădinaru ${ }^{1, *} \mathbb{0}$, Radu Muntean ${ }^{2, *}$, Adrian Alexandru Șerbănoiu ${ }^{1}(\mathbb{D}$, \\ Vasilică Ciocan ${ }^{1}$ and Andrei Burlacu ${ }^{1}$ \\ 1 Faculty of Civil Engineering and Building Services, “Gheorghe Asachi” Technical University of Iași, \\ 700050 Iași, Romania; serbanoiu.adrian@tuiasi.ro (A.A.Ș.); vasilica.ciocan@tuiasi.ro (V.C.); \\ andrei.burlacu@tuiasi.ro (A.B.) \\ 2 Faculty of Civil Engineering, Transilvania University of Brașov, 500152 Brașov, Romania \\ * Correspondence: radu.m@unitbv.ro (R.M.); catalina.gradinaru@tuiasi.ro (C.M.G.); Tel.: +40745183892 (R.M.)
}

Received: 23 February 2020; Accepted: 25 March 2020; Published: 27 March 2020

\begin{abstract}
In the last few years, the building industry experienced a significant development as a response to the demographic growth of human society and to the increasing demand for housing. Their construction involves the traditional use of concrete as a material that provides added strength to the finished building. This is manufactured respecting standard recipes depending on the way of its use. Anyway, all concrete recipes involve the use of mineral aggregates extracted from the riverbed, as is happening in Romania, or rock blocks crushing, as reported in other countries. Under these conditions, the rationalization of the use of natural mineral resources and the identification of new possibilities to reduce their consumption through their replacement with vegetal waste has become an important research issue. In this study, two types of vegetal waste-namely, shredded corn cobs and sunflower stalks-were used to manufacture novel ecological concretes. The vegetal wastes, both in untreated and treated forms (with $20 \%$ and $40 \%$ of sodium silicate solution), were used to replace $50 \%$ of the river (mineral) aggregate volume. The obtained concretes were tested, and the values of some important parameters in the concrete characterization (such as bulk density, water adsorption capacity, compressive strength and splitting tensile strength) were compared with the concrete contains cement CEM II/A-LL 42.5R. The obtained results show that these vegetal wastes have the potential to be used in the manufacturing of new ecological concrete. In addition, this alternative material meets the requirements for the sustainable and healthy development of the environment, offering low-polluting solutions in the context of an increasing demand for constructions.
\end{abstract}

Keywords: vegetal waste; shredded corn cobs; sunflower stalks; green concrete

\section{Introduction}

Besides various benefits, the traditional materials used in the building industry are considered costly and polluting through the process of obtaining them. Concrete, for example, is a widely used material in the constructions industry, with increasing demand due to the global demographic growth. This is because, a concrete building system is considered energy efficient due to its special ability to combine a high thermal mass, very low air infiltration, and a high R-value (thermal resistance) in the exterior walls [1]. In addition, concrete buildings have fewer joints than those made of wood or steel frame, which means a tighter system in which the material itself absorbs and stores heat energy, with a delayed impact of the exterior temperature on the inside environment [2]. 
The major component of the concrete is represented by the mineral aggregates, extracted mainly from the riverbed (as in Romania) [3], or obtained from rock blocks crushing like in other countries [4]. These mineral aggregates are quite widespread natural resources, but this does not mean they are always available for use, and there is no need to be cautious in their extraction.

For example, marine resources (sand and gravel deposited by rivers and glaciers during the ice period) are an important source of mineral aggregates, and their use reduces the need for mine extraction and avoids the use of agricultural areas, which are important benefits for environment [5]. In addition, the delivery distances of the dredged mineral aggregates are generally shorter due to the fact they are landed in ports and their transport is made mainly by sea and not by road [6]. However, the removal of marine sediments will change the height, direction, and distance between waves and in tidal currents, with important consequences for marine wildlife, ecosystems, and navigation activities [7].

In the regions that do not have sand and gravel, and where mineral aggregates are obtained from crushed stone extracted from very large depths, which involves very high costs [5]. In this case, the obtaining of mineral aggregates is a fairly polluting process for the environment, mainly due to the greenhouse emissions. The environmental impacts associated with mineral aggregate mining are represented by acidic mine drainage, conversion of land use accompanied by loss of habitat for humans and animals, noise, dust, blasting effects, erosion, sedimentation, and relief changes. These are related to the fact that mineral aggregates such as sand, gravel, and bedrock are extracted from pits and quarries (open-pit mining and quarrying are commonly used and, in special cases, underground mining). Their presence means the loss of agricultural land and the shift of land use from terrestrial to lake habitats, by-products resulting from aggregate processing, and an impact on physical infrastructure (i.e., buildings, roads, and dams) [4,8-10]. In some cases, land intended to be developed for mineral aggregates extraction can have rare geomorphic characteristics or can be the habitat for rare and endangered species. Mining in such areas can lead to serious and long-lasting environmental consequences in the site vicinity or even very far away locations form it. Mineral aggregate sites can disturb surrounding areas, mainly via truck traffic and air pollution, with a negative impact for residents in the form of noise and visual disamenities. Mineral aggregate mining can lead to the release of deleterious sediments, salt, and chemicals into the watercourses, soil, and air $[6,9,11]$. To estimate the real impact of this activity, it is necessary to consider that, in Europe, there are over 30,000 extraction sites, which produce around seven tons of aggregate per EU citizen [10] - the global request for mineral aggregates is about 22 billion tons per year [12].

Therefore, even if the dredging of marine mineral aggregates is more advantageous than digging or mining, it must adhere to the principles of sustainable management of long-term availability of resources, minimizing the negative impact on the environment and the socio-economic impact of the extraction process. This is because both methods deplete a category of natural resources, alter the landscape, and affect the natural habitat of different plants and animals.

However, the environmental ethics principles in the building industry have to consider a close relationship between nature and buildings, a harmony of human' society development in the context of all that nature means. This means that a sustainable building industry should take into account environmental problems such as the natural resources consumption, pollutants, and excessive energy usage, which means that the industry needs to work simultaneously in three interdependent directions-social, environmental, and economic [13].

This is the main reason why, in recent years, various alternatives such as waste fly ash; blast furnace slag; silica fume; plants ashes such as corn cob ash, wheat ash, and rice husk ash; recycled aggregates from demolitions; expanded perlite; expanded clay or expanded polystyrene; PET (polyethylene terephthalate) fibers; steel fibers; glass; plastics; lignocellulosic materials; or agricultural waste have been used as alternatives to reduce the amount of mineral aggregates needed to manufacture the concrete [14-24]. Among all these materials, the use of agricultural waste has become increasingly popular due to the improved characteristics of the obtained concrete, which are mainly related to 
thermal and acoustic insulation, lower costs, and environmental protection by reducing the use of the conventional raw materials $[1,25-30]$.

Among many agricultural wastes studied for their suitability in building sector, corn cobs and sunflower have the advantage of worldwide available [31,32]. In addition, these materials are easy to process using local resources without generating extra costs because harvesting and storage is done using common agricultural equipment. Moreover, it has been shown that the use of such agricultural waste can result in high-quality aggregates for building materials using simple processing and low sintering temperature, further contributing to the limitation of environment pollution [33]. For example, the addition of corn cobs and sunflowers to concrete manufacturing improves thermal and acoustic insulation [1,26-30], with good resistance to sodium sulphate [34]. The authors of reference [35] used corn cob as pore-forming agent in lightweight clay bricks, obtaining apparent and bulk density, flexural strength, decreased linear shrinkage, and increased water absorption and porosity. Shredded corn cobs were used in the production of lightweight concrete as an alternative sustainable solution compared to the light aggregates used today, such as those of expanded clay, cork, or expanded polystyrene. The authors of reference [36] made a lightweight concrete from corn cobs in a 6/1/1 ratio (crushed corn chips/Portland cement/water) and an expanded clay concrete in the same ratio (expanded clay/Portland cement/water), obtaining lower mechanical characteristics than the classical concrete but also very low densities, which makes it usable in non-structural applications. The authors of reference [28] conducted a research on shredded corn cobs used as aggregates to produce lightweight concrete masonry blocks. The density of the obtained products was $1680 \mathrm{~kg} / \mathrm{m}^{3}$, a value that places the concrete obtained into lightweight concrete category, according to the regulations in force. To reduce the water absorption and to improve the adhesion between concrete and aggregates, the corn cobs were coated with a cement paste. The tests performed showed a good resistance to repeated cycles of freeze-thaw. The authors of reference [27] studied the properties of concrete with sunflower aggregates, compared to those of concrete with hemp aggregates, in a binder/aggregate ratio of 2 . The tests performed on concrete with sunflower aggregates showed a thermal conductivity of $0.096 \mathrm{~W} / \mathrm{mK}$ and an average compression strength of $0.5 \mathrm{~N} / \mathrm{mm}^{2}$ determined at 60 days. Also, [8] showed that aggregates from sunflower and hemp stalks have a similar honeycomb structure and similar chemical composition. The authors developed a concrete with sunflower aggregates and binder based on limestone and pumice, with the ratio binder/aggregates equal to 18. The compressive strength at 28 days of this type of concrete was $2.52 \mathrm{~N} / \mathrm{mm}^{2}$. The same concrete recipe, but which included hemp aggregates, had a compressive strength of $2.77 \mathrm{~N} / \mathrm{mm}^{2}$. [37] developed a composite material of chitosan and particles of sunflower stalks, with a thermal conductivity of $0.056 \mathrm{~W} / \mathrm{mK}$ and a compressive strength of $2 \mathrm{~N} / \mathrm{mm}^{2}$, in the case of a recipe with $4.3 \%$ chitosan and sunflower particles bigger than $3 \mathrm{~mm}$. All these research findings suggest that the use of such agricultural wastes in concrete production can be a viable alternative to help in reducing the environmental impact associated with the mineral aggregate extraction industry in the context of the sustainable development of human society.

In this study, shredded corn cobs and sunflower stalks were used to manufacture novel ecological concretes. These vegetal wastes were used to replace $50 \%$ of the river (mineral) aggregate volume. The obtained concretes were tested, and the values of some important parameters in the concrete characterization (such as bulk density, water adsorption capacity, compressive strength, and splitting tensile strength) were compared with the concrete contains cement CEM II/A-LL 42.5R. The aim of this research was to make a material with alternative applicability in building elements where ordinary concrete would be less efficient. This ecological alternative complies with the criteria of sustainable development, offering non-polluting variants in the context of a highly industrialized society.

\section{Materials and Methods}

This research implied the development of concrete recipes with corn cobs and sunflower stalks as partial replacements for the mineral aggregates. As a starting point, we established a reference 
concrete $(\mathrm{RC})$ recipe with conventional components of $\mathrm{C} 30 / 37$ strength class and $8 \mathrm{~mm}$ the maximum size of the aggregates, calculated according to reference [38].

The reference concrete contains CEM II/A-LL 42.5R cement, sand (0-4 mm diameter), and river gravel (sort 4-8 mm). A superplasticizer based on policarboxilateter (Sika Plast 140, produced by Sika Romania) was used to reduce the water requirements while maintaining workability, and an accelerator based on rhodanid (Sika BE 5, produced by Sika Romania) was used for hardening the concrete and accelerating the cement hydration process. The water/cement ratio was 0.43 .

The formulas for vegetal concrete implied the use of shredded corn cobs and sunflower stalks as $50 \%$ by volume replacement of the river (mineral) aggregates. The procedure for obtaining the vegetal aggregates from corn cobs and sunflower stalks, respectively, was as follows:

From maize plants, only corn cobs (no husks or grains) (Figure 1a) were harvested, and only stalks without leaves and hats were harvested from sunflower plants (Figure 1b).

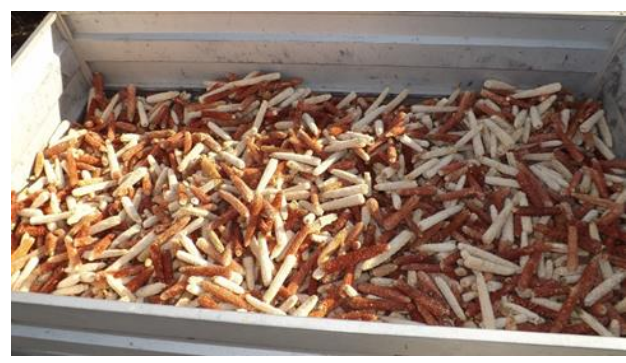

(a)

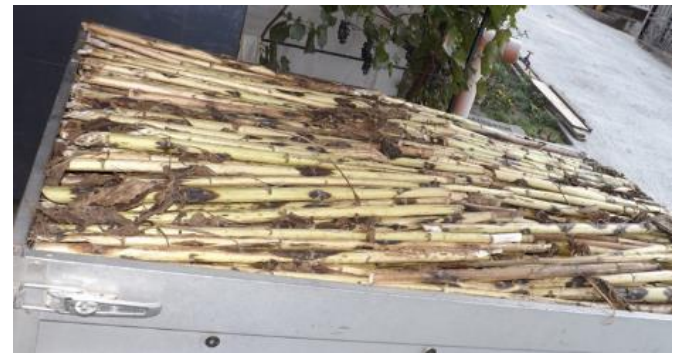

(b)

Figure 1. Vegetal material after harvesting: (a) corn cobs; (b) sunflower stalks.

After harvesting, the sunflower stalks were left to dry in stacks in the environment (Figure 2).

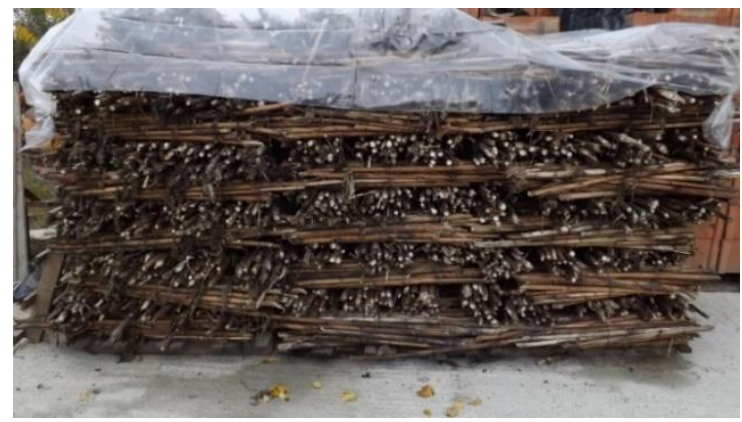

Figure 2. Sunflower stalks drying.

Corn cobs were shredded in granules smaller than $6 \mathrm{~mm}$ using a mill for grinding animal feed (Figure 3a). Sunflower stalks were shredded with the same mill, resulting in granules with a diameter of less than 5-6 $\mathrm{mm}$ and fibers less than $25 \mathrm{~mm}$ long (Figure $3 \mathrm{~b}$ ).

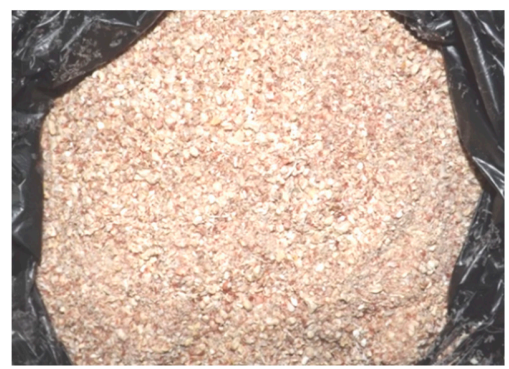

(a)

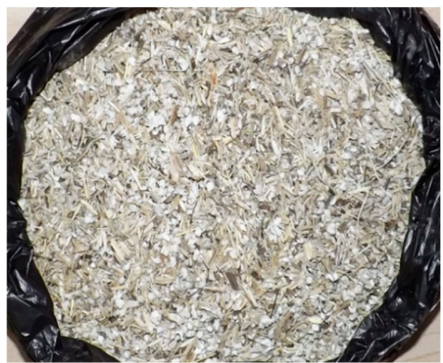

(b)

Figure 3. The aspect of vegetal material after shredding: (a) corn cobs; (b) sunflower stalks. 
After shredding, the vegetal material was treated with sodium silicate solution by immersion (Figure 4).

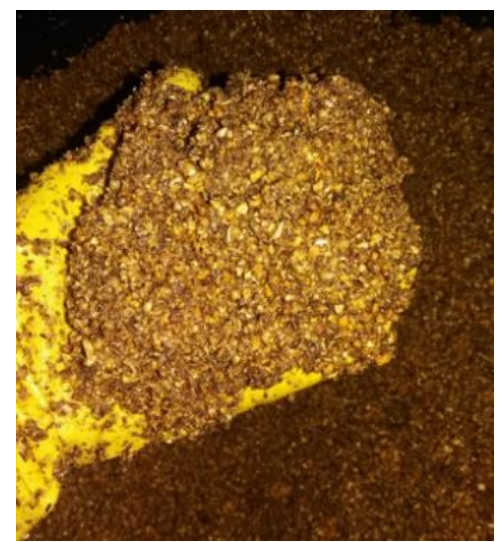

(a)

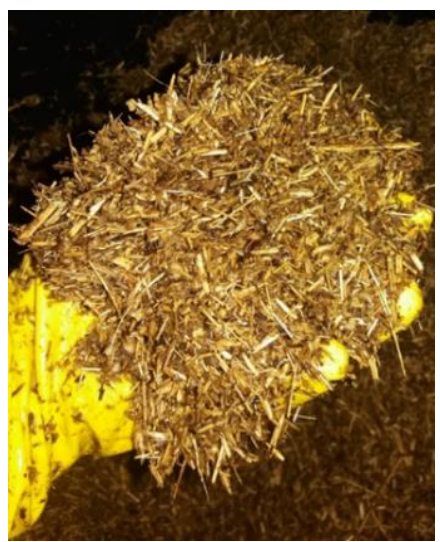

(b)

Figure 4. The aspect of vegetal material after shredding and treatment with sodium silicate solution, in a wet state: (a) corn cobs; (b) sunflower stalks

After immersion in the sodium silicate solution, the vegetal material was left to dry at a temperature of about $25-27^{\circ} \mathrm{C}$ (Figure 5).

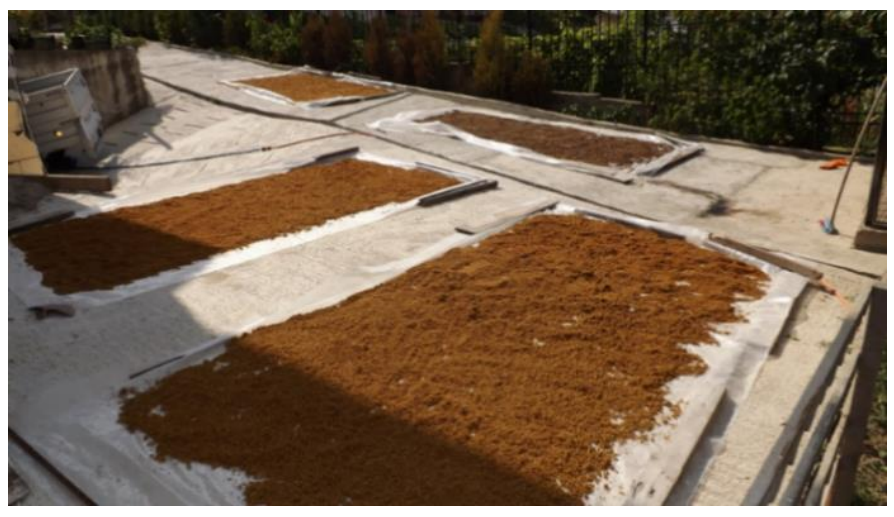

Figure 5. The drying of the vegetal material at a temperature of about $25-27^{\circ} \mathrm{C}$ after the treatment with a sodium silicate solution.

After drying to a constant mass, the plant material was used as a plant aggregate in the concrete composition (Figure 6).

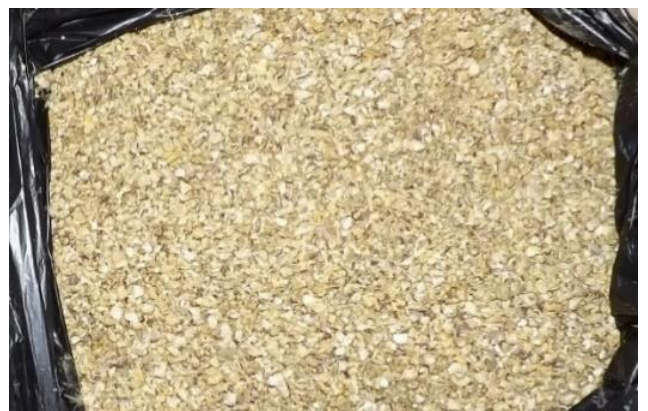

(a)

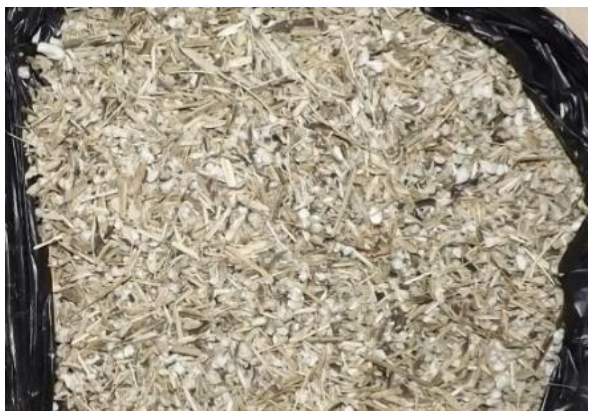

(b)

Figure 6. The aspect of vegetal material after shredding and treatment with sodium silicate solution, in a dry state: (a) corn cobs; (b) sunflower stalks. 
The vegetal aggregates were used in three forms - untreated, treated with $20 \%$ sodium silicate solution, and treated with $40 \%$ sodium silicate solution. Their visual aspect was the same no matter the solution concentration (Figure 7c,f).

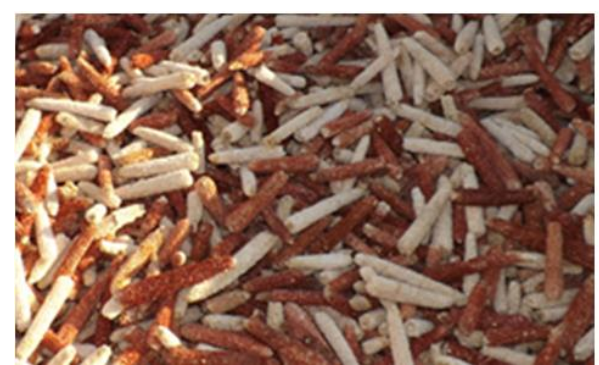

(a)

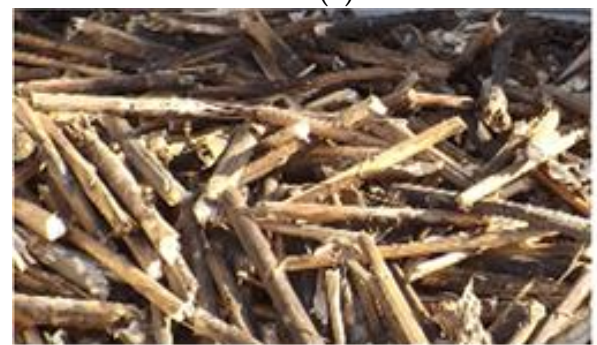

(d)

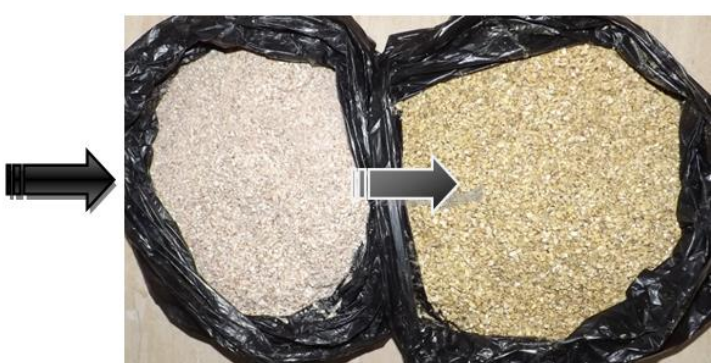

(c)

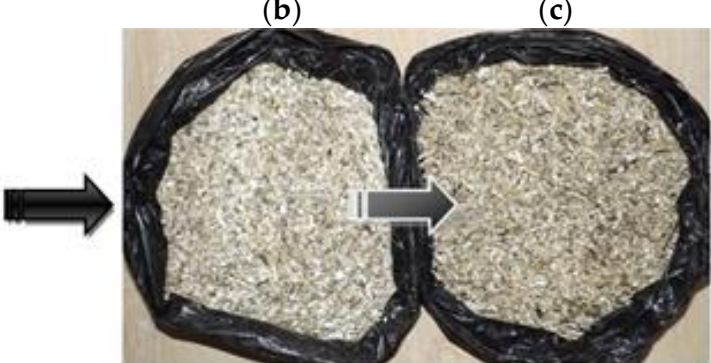

(e) (f)

Figure 7. Corn cobs and sunflower stalks aspect—from stalk to treated granules: (a) corn cobs; (b) untreated shredded corn cobs; (c) treated shredded corn cobs; (d) sunflower stalks; (e) untreated shredded sunflower stalks; (f) treated shredded sunflower stalks.

Sodium metasilicate compound $\left(\mathrm{Na}_{2} \mathrm{SiO}_{3}\right)$, also known as glass water or liquid glass, is available in liquid and solid forms and is used as passive fire protection for concrete and to protect against termites, rot, and degradation in refractories, textiles, woodworking, and automobiles.

To reduce the water absorption capacity of the vegetal aggregates, the shredded granules were treated first with $20 \%$ sodium silicate solution. Then, they were dried, and their bulk density and water absorption capacity were measured.

Because the objective was to reduce the water absorption capacity for the plant aggregates as much as possible, other vegetal aggregates were immersed in a $40 \%$ concentrated solution of sodium silicate, dried, and then their bulk density and water absorption capacity measured, as in the first case.

An additional amount of water, varying according to the specific absorption capacity of the plant aggregates, was added to the concrete recipes with vegetal aggregates at a rate calculated to provide a water/cement ratio of 0.43 . We developed the following concrete recipes:

- $\quad \mathrm{RC}$-reference concrete;

- CUCC - concrete with untreated granules of corn cob;

- CTCC20-concrete with treated granules of corn cob with $20 \%$ sodium silicate solution;

- CTCC40-concrete with treated granules of corn cob with $40 \%$ sodium silicate solution;

- CUSF-concrete with untreated sunflower granules;

- CTSF20-concrete with treated sunflower granules with $20 \%$ sodium silicate solution;

- CTSF40 - concrete with treated sunflower granules with $40 \%$ sodium silicate solution.

For testing their compressive strength, $150 \times 150 \times 150 \mathrm{~mm}$ cubic molds were used, while for testing their flexural and splitting tensile strength, $100 \times 100 \times 500 \mathrm{~mm}$ prism molds were used. There were three replicates for each test. All the tests were performed at the age of 28 days, according to the current technical norms [39-42]. 


\section{Results and Discussions}

\subsection{Evaluation of Vegetal Aggregate Bulk Density and Water Absorption Capacity}

Table 1 shows the determined values for bulk density and water absorption capacity for the vegetal aggregates.

Table 1. The bulk density and water absorption capacity of the vegetal aggregates.

\begin{tabular}{cccc}
\hline $\begin{array}{c}\text { Vegetal } \\
\text { Aggregates }\end{array}$ & Treatment Applied & $\begin{array}{c}\text { Bulk Density } \\
{\left[\mathbf{k g} / \mathbf{m}^{\mathbf{3}}\right]}\end{array}$ & $\begin{array}{c}\text { Water Absorption } \\
\text { Capacity [\%] }\end{array}$ \\
\hline \multirow{3}{*}{ Corn cobs } & no treatment & 281.25 & 294 \\
& 20\% sodium silicate solution & 242.19 & 181 \\
& $40 \%$ sodium silicate solution & 398.43 & 127 \\
Sunflower stalks & no treatment & 207.03 & 402 \\
& 20\% sodium silicate solution & 164.06 & 292 \\
& $40 \%$ sodium silicate solution & 328.12 & 100 \\
\hline
\end{tabular}

In the case of corn cob granules, the treatment with $20 \%$ sodium silicate solution resulted in a decrease of water absorption by $38.44 \%$; in the case of corn cob granules treated with $40 \%$ sodium silicate solution, it was $127 \%$, which means a $56.80 \%$ reduction compared to the untreated granules. In the case of sunflower stalk granules, the treatment with $20 \%$ sodium silicate solution resulted in a reduction of water absorption of $52.24 \%$; in the case of sunflower stalk granules treated with $40 \%$ sodium silicate solution, it was $100 \%$, meaning a $75.12 \%$ reduction comparative to the untreated granules.

\subsection{Evaluation of the Vegetal Concrete Density}

The density evolution curves for the obtained concrete are showed in Figure 8. The highest slope of the curve was registered by CUCC. This concrete variant involved the greatest quantity of added water besides the quantity calculated for cement hydration and, implicitly, the greatest quantity of water lost during concrete curing. This loss of water led to the lowest mechanical strengths resulting from the weaker connection at the interfacial transition zone between the vegetal aggregates and the cement paste.

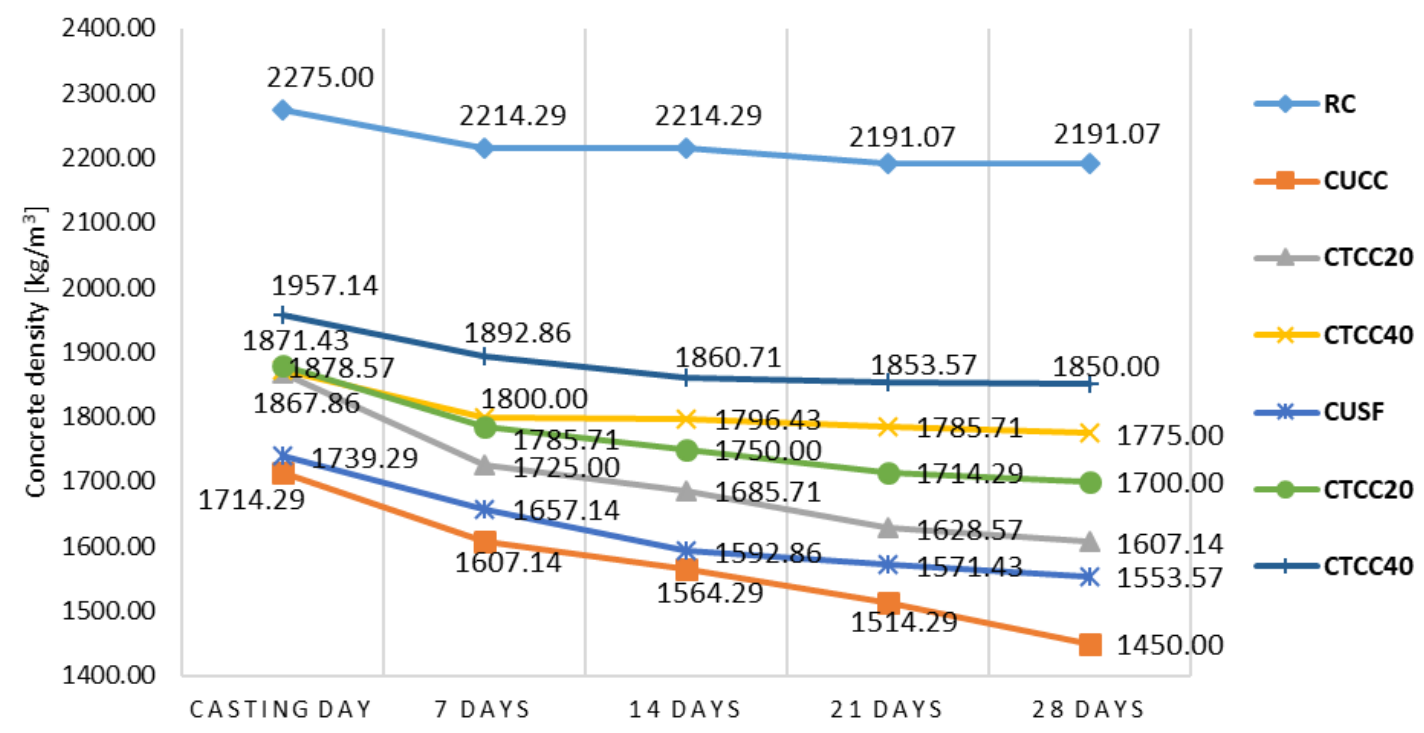

Figure 8. The evolution of concrete density, from casting to the age of 28 days $\left(\mathrm{kg} / \mathrm{m}^{3}\right)$.

The increase in the density of the concrete with treated corn cobs in both versions was about the same intensity as to the sunflower concrete: CTCC20 and CTSF20 had an increase in density of 
approximately $10 \%$, and CTCC40 and CTSF40 had an increase of approximately $20 \%$ (values reported to CUCC and CUSF, respectively).

\subsection{Evaluation of the Compressive Strength of Concretes with Vegetal Aggregates}

The results obtained after testing the compressive strength for the concrete described above are presented in Figure 9.

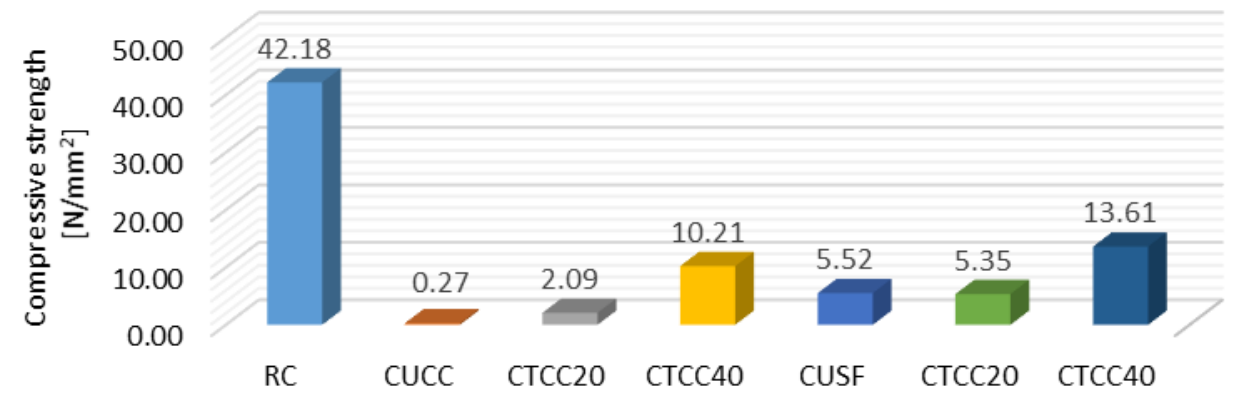

Figure 9. Compressive strength for the developed concrete recipes $\left(\mathrm{N} / \mathrm{mm}^{2}\right)$.

A replacement of $50 \%$ of mineral with vegetal aggregates led to a significant decrease compared to the reference concrete. On the other hand, treating the vegetal aggregates with a $40 \%$ sodium silicate solution led to an important improvement in terms of compressive strength compared to the concrete with untreated vegetal aggregates.

The concrete with untreated corn cobs was shown to have a very low compressive strength, recording a value of only $0.27 \mathrm{~N} / \mathrm{mm}^{2}$ compared to the one of reference concrete of $42.18 \mathrm{~N} / \mathrm{mm}^{2}$. This particularly low value is due to the presence of a significant quantity of water) the inadequate moisture of the specimens was visible to the naked eye). The water absorbed by the vegetal part of the concrete was highest compared to the other concrete recipes, and, as shown in Figure 9, it was the recipe with the highest decrease in density. This drop means that it had the largest quantity of evaporated water (leaving the concrete structure), which left behind an increased volume of air and very poor interface links between aggregates and the cement paste.

The corn cobs treatment with $40 \%$ sodium silicate solution increased the compressive strength of concrete 30 times comparative to the concrete with untreated plant aggregates, and about 5 times comparative with the first treatment variant, resulting in a value of $10.21 \mathrm{~N} / \mathrm{mm}^{2}$. This significant improvement was due to the dramatic decrease in corn cobs absorption capacity (from $294 \%$ in the untreated variant up to $127 \%$ in the variant treated with $40 \%$ solution).

Regarding the concrete with sunflower plant aggregates, it recorded a compressive strength much higher than that with corn cobs, especially in the untreated aggregate variants $\left(5.52 \mathrm{~N} / \mathrm{mm}^{2}\right)$ and that treated with $20 \%$ sodium silicate solution $\left(5.35 \mathrm{~N} / \mathrm{mm}^{2}\right)$, despite having an absorption capacity higher than that of corn cobs. This leads to the conclusion that a high compressive strength of CUSF compared to CUCC (by approximately 15 times) contributed to the strength of the plant aggregates themselves. In the composition of the sunflower stem, the bark has a more rigid, woody, and fibrous structure with mechanical characteristics superior to corn cobs. Contrary to expectations, treatment in the first variation of sunflower aggregates led to a small decrease in compression strength, a result that can be explained by the additional amount of water.

Treatment of sunflower aggregates with $40 \%$ sodium silicate solution resulted in a $146.5 \%$ increase in compressive strength of concrete with these aggregates compared to the concrete with untreated sunflower aggregates, and it was 33.3\% higher than of the concretes with corn cob aggregates treated with the same concentration of sodium silicate solution. In conclusion, sunflower concrete registered improved performance in compressive strength compared to corn cob concrete. 
By analyzing the concrete compressive strength in comparison with the capacity of water absorption for the aggregates involved (Figure 10), the reduction of the last parameter determined the increase of the compressive strength, both for the corn cob concrete and for the sunflower concrete.

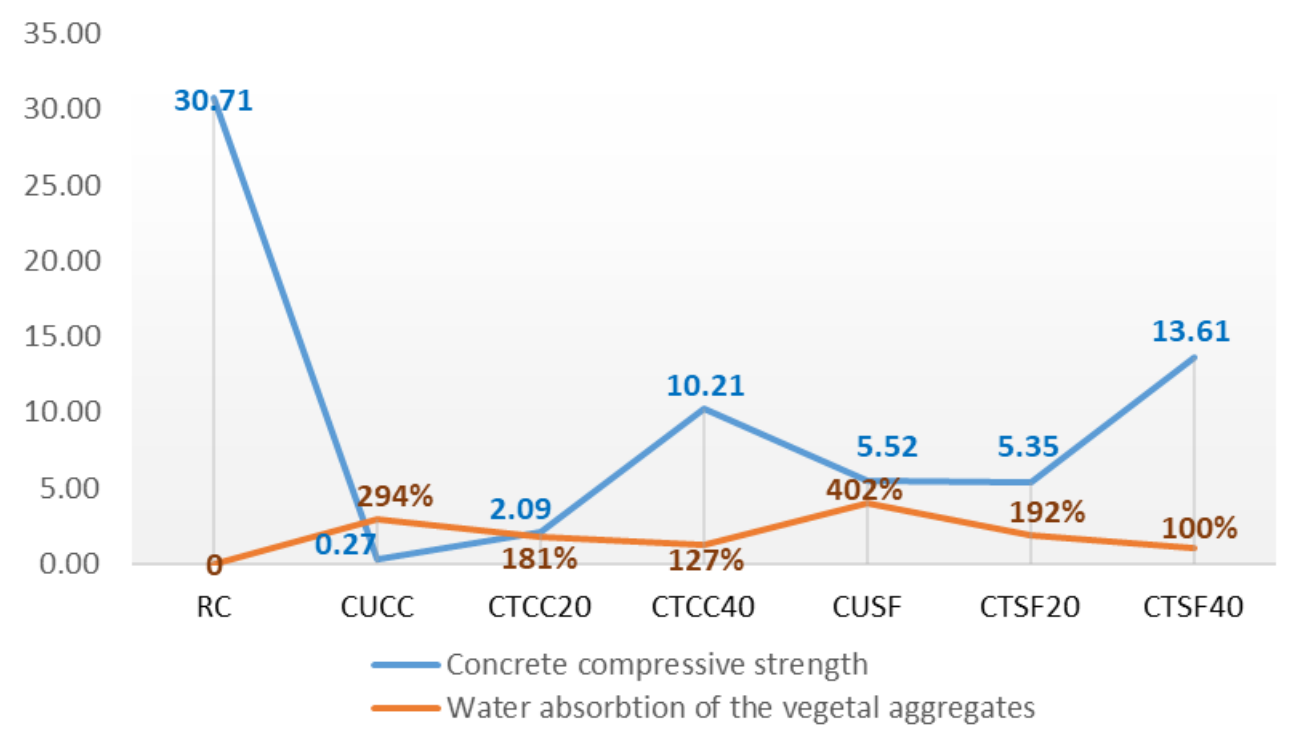

Figure 10. Concrete compressive strength after 28 days of curing $\left(\mathrm{N} / \mathrm{mm}^{2}\right)$, comparatively presented with water absorption capacity of the vegetal aggregates (\%).

In its natural form, the sunflower stalk is made up of a fibrous, rigid coat (the bark) and a marrow with very porous structure and a much smaller density than the bark. During the shredding process, the marrow underwent some compaction of its volume, and the ratio between it and the fibrous part of the stem was altered in the opposite direction to that of the normal, natural state of the sunflower stalk. This led to a predominant share of the fibrous part in the composition of the shredded sunflower granules, which gives superior mechanical strength to these plant aggregates.

In the corn cob structure, there is no great difference between its component layers, and the mechanical strengths of the cobs are noticeably lower than those of the sunflower stalks. Thus, in the variants involving untreated vegetal granules, although the water absorption of the sunflower aggregates was higher $(402 \%)$, the concrete with these aggregates was characterized by much higher compressive strength values than those recorded for the corn cob concretes due to the more rigid structure of the sunflower stalk. This characteristic of sunflower aggregates compensated for and exceeded its increased rate of water absorption due to the more porous structure of the marrow of the sunflower stalk.

\subsection{Evaluation of the Flexural Tensile Strength of Concretes with Vegetal Aggregates}

The concrete specimens with untreated corn cob aggregates suffered damage during the curing process due to the concrete shrinkage as a consequence of the water loss from its structure and the decrease in the volume of the plant aggregates, thus developing aggregate-cement interface forces that were opposite and parallel to the prism length and high enough to cause a continuous crack across the entire cross section of the prisms.

Treating the corn cobs with $20 \%$ sodium silicate solution prevented the occurrence of that shrinkage concrete crack but showed a very low bending strength $\left(0.68 \mathrm{~N} / \mathrm{mm}^{2}\right)$ compared to that determined for RC $\left(3.44 \mathrm{~N} / \mathrm{mm}^{2}\right)$. A higher concentration for the sodium silicate solution applied to the corn cob aggregates led to a significant increase for tensile strength of the afferent concrete, CTCC40, by $188.2 \%$ $\left(1.96 \mathrm{~N} / \mathrm{mm}^{2}\right)$ (Figure 11). 


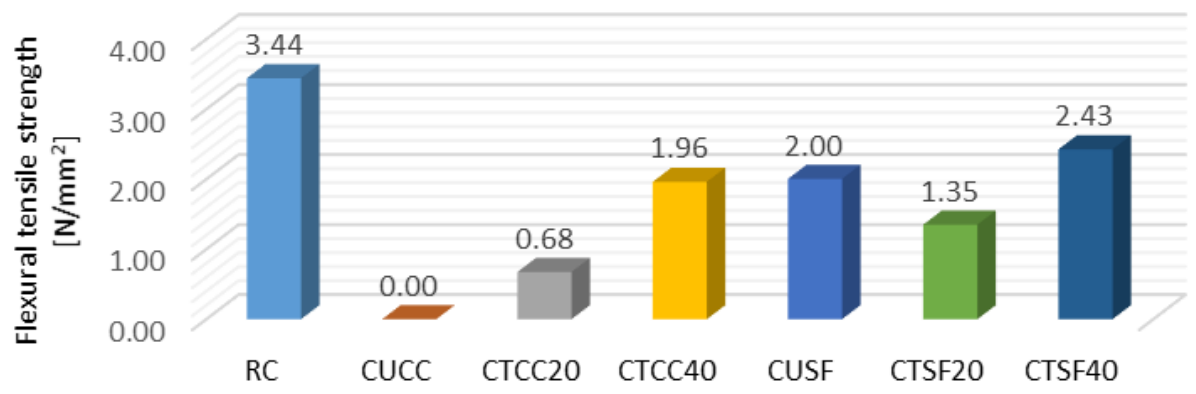

Figure 11. Concrete flexural tensile strength $\left(\mathrm{N} / \mathrm{mm}^{2}\right)$.

The sunflower concrete in its variant with untreated aggregate showed a flexural tensile strength slightly superior to the one of the concrete with corn cobs treated with the more concentrated sodium silicate solution $\left(2.0 \mathrm{~N} / \mathrm{mm}^{2}\right)$, due to the fiber form of the sunflower aggregates, which somehow reinforced the structure of the concrete. Treating sunflower aggregates with $20 \%$ glass water resulted in an unexpected drop in the flexural tensile strength by $32.5 \%\left(1.35 \mathrm{~N} / \mathrm{mm}^{2}\right)$, which was probably due to the wood fibers stiffening, which led to decreased flexibility and the development of a casual character. Applying 40\% glass water solution to the sunflower aggregates further increased the bending strength up to $2.43 \mathrm{~N} / \mathrm{mm}^{2}$ (Figure 11). This increase is determined by higher wood fiber stiffening (increasing the concentration of the glass water solution leads to a weight gain for the aggregates that can better oppose the bending forces).

In conclusion, in terms of flexural tensile strength, sunflower concrete had the best values in all variants of aggregate treatment, with the highest strength obtained by CTSF40 of $2.43 \mathrm{~N} / \mathrm{mm}^{2}$ being below the value recorded by $\mathrm{RC}\left(3.44 \mathrm{~N} / \mathrm{mm}^{2}\right)$.

\subsection{Evaluation of the Splitting Tensile Strength of Concretes with Vegetal Aggregates}

Concrete recipes with plant aggregates recorded values well below those of the RC in the case of splitting strength. The most resistant variant (with sunflower treated with $40 \%$ sodium silicate solution) recorded values that were approximately $58 \%$ lower than the reference $\left(1.27 \mathrm{~N} / \mathrm{mm}^{2}\right)$ (Figure 12).
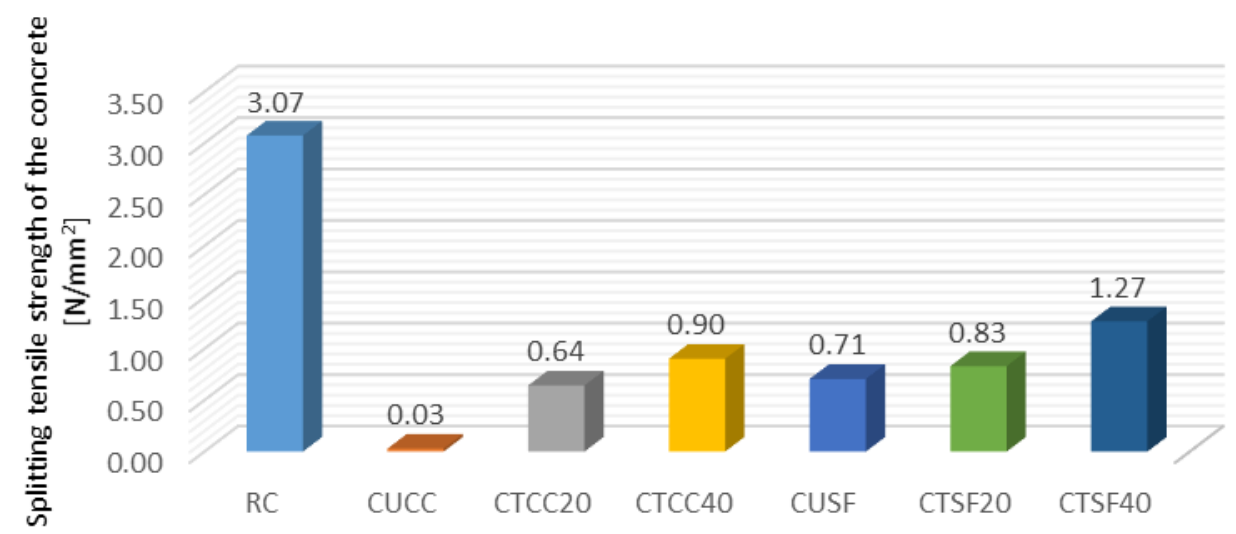

Figure 12. Concrete splitting tensile strength $\left(\mathrm{N} / \mathrm{mm}^{2}\right)$.

CUCC showed a very low splitting strength, which was almost impossible to test $\left(0.03 \mathrm{~N} / \mathrm{mm}^{2}\right)$ (Figure 12). The explanation is similar with that regarding the compressive strength: the specimens showed inadequate moisture, which was visible to the naked eye. The water absorbed by the vegetal part of the concrete was higher for this concrete recipe than for the other vegetal aggregate concrete recipes. Thus, the amount of water absorbed led to the greatest decrease in density during the curing period of 28 days, causing a considerable evaporation of water from the concrete structure, which 
left behind an increased volume of air and a very weak interface between the aggregates and the cement paste.

The treatment of corn cobs led to an increased splitting tensile strength of the concrete compared to the one with untreated aggregates, but it was not more than $30 \%$ of the value obtained by RC $\left(0.64 \mathrm{~N} / \mathrm{mm}^{2}\right.$ for CTCC20 and $0.90 \mathrm{~N} / \mathrm{mm}^{2}$ for CTCC40) (Figure 12).

Sunflower concretes recorded superior splitting tensile strengths to corn cob concretes, in addition to compressive and flexural tensile strength tests. In the case of concrete with untreated sunflower granules, a strength of $0.71 \mathrm{~N} / \mathrm{mm}^{2}$ was obtained, which was higher than the concrete with corn cobs treated with the $20 \%$ sodium silicate solution. The first treatment of sunflower granules led to a slight increase in concrete splitting tensile strength, while the second treatment variant resulted in a much higher value of about $79 \%$ compared with that of concrete with untreated aggregates.

\section{Application Areas of the Novel Concrete with Plant Aggregates}

According to our presented test results, plant aggregates may be successfully used for concrete, leading to a reduction of mineral aggregates using of around $900 \mathrm{~kg} \mathrm{per} \mathrm{m}^{3}$ of concrete when compared to conventional concrete. If we consider a replacement of $50 \%$ by volume ratio of mineral aggregates in the developed concrete recipes, this means a $50 \%$ reduction of the mineral aggregates used for concrete production. Indeed, the plant aggregates can be used only in specific concrete types due to their mechanical strength limitations; in general, concrete with plant aggregates cannot be used in structural purposes. The concrete with corn cob or sunflower aggregates can be used for lightweight concrete screeds, lightweight substrates/subfloors, or acoustic mats. This is in line with the results presented in a previous made with two concrete recipes with the best mechanical strengths, CTCC40 and CTSF40, developed by the authors of reference [25]. The aforementioned study presented some acoustic characteristics, such as the noise reduction coefficient (NRC) and real sound absorption coefficient, of the CTCC40 and CTSF40, which were noted in that paper as mc-corn and mc-sun, respectively. The authors obtained significantly better results for the plant concrete comparing to conventional concrete. CTCC40 had a NRC of 0.193 in the case of the $40 \mathrm{~mm}$ thickness sample, comparing to 0.157 registered by conventional concrete used as a reference. Its real sound absorption coefficient measured on a frequency of $2000 \mathrm{~Hz}$ was 0.427 , compared to 0.279 for the reference. These values were obtained on an $80 \mathrm{~mm}$ thick sample. The CTSF40 (mc-sun) registered a NRC of 0.177 and a real sound absorption coefficient of 0.418 in the same conditions of analysis.

It is well known that lightweight concretes of any kind provide better thermal insulation than normal weight concrete. By using lightweight concrete with corn cob or sunflower aggregates as screeds in a building, a reduction of the thermal bridging at the slabs level can be obtained. This means a reduction of heat transfer and a cold sensation at floor level.

Vegetal concrete can be used in modular elements for buildings closures, such as bricks or panelized walls manufactured off site and then assembled with minimal site disturbance and no waste. As blocks, the lightweight vegetal concrete can be used to develop sound-insulating blocks or lightweight blocks for partition walls. Also, it can be used to make panels for partition walls or sound-absorbent panels due to the material porosity ensured by the chopped corn cobs or sunflower stalks. The production of building elements in the form of cast blocks made of lightweight concrete with vegetal aggregates has lower energy consumption compared to the production of bricks (ceramic blocks), which require thermal treatments/burning in furnaces.

The use of lightweight concrete with vegetal aggregates can increase work productivity by replacing partition walls made of bricks with walls cast in formworks or prefabricated walls while keeping the main features of sound and thermal insulation as well as mechanical characteristics at a satisfactory level.

If the vegetal lightweight concrete is used in mortar for masonry and/or plastering, it will help to correct small-scale thermal bridging. It can ensure a continuity of the thermal insulation when it is used concomitant as screed and plaster in a building. 
Lightweight concrete with corn cob or sunflower aggregates can also be used on flat roofs to level and regularize the support under waterproofing membranes and provide thermal insulation against heat and cold.

By using lightweight concrete, obtained by replacing the usual aggregates with vegetal ones (like corn cob or sunflower aggregates), the realization of non-structural elements of a building (concrete screeds, closing walls or partitions, finishes, etc.) leads to the reduction of the total weight of the building, resulting in favorable effects on its behavior during earthquake.

It is also possible to increase the efficiency of the machines and equipment used in the production, transport, and casting of concrete (concrete plants, concrete mixers, cranes, pumps, etc.) and a decrease in their energy consumption due to the smaller weight per unit volume of the concrete used in non-structural purposes.

The use of concretes with vegetal aggregates can help to increase the sustainability of buildings and reduce their total carbon footprint by replacing some raw materials that are increasingly difficult to obtain with natural, renewable materials that obtained with much smaller energy consumption.

Taking all of this into account, it can be concluded that CTCC40 and CTSF40 can widely be used in construction industry.

\section{Conclusions}

The present study aimed to present the benefits of mineral aggregates replacement in concrete by plant aggregates in the context of sustainable development and environmental protection. The developed vegetal concrete represents a variant of innovative and sustainable building material that could result in mineral aggregate savings and a positive effect on global health and environment.

In our research, we used corn cobs and sunflower stalks as plant aggregates, which were previously treated with sodium silicate solution. Some physical properties of vegetal concrete, especially thermal and acoustic properties, were reported to be greatly altered by the presence and the amount of absorbed water. The increased porosity and internal structure of the porous plant aggregates are responsible for the high absorption of water and their retention capacity. Due to high moisture absorption capacity, the durability of vegetal concrete represents a challenge. Using the shredded corn cobs and sunflower stalks as partial replacement for aggregates in concrete production requires some treatments to be applied in order to reduce their water absorption capacity and increase the interface compatibility with the concrete cement paste. To accomplish this objective, we adopted a treatment of vegetal granules with sodium silicate solution. As a result of the performed treatment with sodium silicate solution, we obtained a significant reduction in water absorption capacity.

The case study results showed an increase in concrete density when treated vegetal aggregates were used of approximately $10 \%$ in the case of using a solution of sodium silicate of $20 \%$ concentration and of approximately $20 \%$ in the case of $40 \%$ sodium silicate solution compared to the concrete with untreated vegetal aggregates. The treatment of vegetal aggregates with $40 \%$ solution of sodium silicate solution led to a significant improvement in the compressive strength of the concrete compared to the that with untreated plant aggregates. Sunflower concrete's mechanical strengths is superior to corn cob concrete.

By analyzing the compressive strength in comparison to the water absorption capacity of the aggregates involved, it was observed that reducing the water absorption capacity of the vegetal aggregates resulted in an increase of the compressive strength for both the corn cob concrete and the sunflower concrete.

From a mechanical properties point of view, the investigated concrete in our study can be used for concrete screeds or for modular elements for buildings closures, such as bricks or prefabricated walls that are manufactured off site and then assembled with minimal site disturbance and no waste. The obtained results also showed that vegetal aggregates may be successfully used in the manufacturing of concrete, leading to a reduction of mineral aggregate use of around $900 \mathrm{~kg} \mathrm{per}^{3}$ of concrete, as comparing to the conventional concrete. The use of such plant aggregates is an essential component of 
sustainable development by reducing the usage of mineral aggregates. This is an ecological alternative that meets the sustainable requirements for a healthy environment, offering low-pollutant alternatives in the context of an increasing demand for construction materials.

Author Contributions: Conceptualization, A.A.S.; Funding acquisition, R.M.; Investigation, C.M.G.; Methodology, C.M.G., V.C. and A.B.; Writing-original draft, C.M.G.; Writing—review \& editing, C.M.G. and R.M. All authors have read and agreed to the published version of the manuscript.

Funding: This research did not receive any specific grant from funding agencies in the public, commercial, or not-for-profit sectors.

Acknowledgments: Special thanks to the Sika Romania representatives for their technical support and for providing the necessary additives in order to accomplish this research.

Conflicts of Interest: The authors declare no conflict of interest.

\section{References}

1. Pinto, J.; Paiva, A.; Varum, H.; Costa, A.; Cruz, D.; Pereira, S.; Fernandes, L.; Tavares, P.; Agarwal, J. Corn's $\mathrm{cob}$ as a potential ecological thermal insulation material. Energy Build. 2011, 43, 1985-1990. [CrossRef]

2. USGBC (United States Green Building Council). LEED v4 Reference Guide for Homes Design and Construction. 2013. Available online: https://www.usgbc.org/sites/all/assets/section/files/v4-guide-excerpts/ Excerpt_v4_HOMES.pdf (accessed on 15 October 2019).

3. Gradinaru, C.M. The environmental impact of concrete production and its greening necessity. In Resilient Society Environment and Human Action Series A; Ozunu, A., Nistor, I.A., Petrescu, D.C., Burny, P., Petrescu-Mag, R.M., Eds.; Les Presses Agronomiques: Gembloux, Belgium; Bioflux: Cluj-Napoca, Romania, 2017; pp. 81-94.

4. Hicks, L. Aggregates Supply in England: Issues for Planning; Open Report no. 059; British Geological Survey: Nottingham, UK, 2008; Available online: http://nora.nerc.ac.uk/id/eprint/5215/1/OR08059.pdf (accessed on 19 November 2019).

5. Langer, W.H.; Drew, L.J.; Sachs, J.S. Aggregate and the environment. In American Geological Institute Environmental Awareness Series; American Geological Institute: Silver Spring, MD, USA, 2004; Volume 8, p. 64.

6. Grant, A. Estimating the Marginal Effect of Pits and Quarries on Rural Residential Property Values in Wellington County, Ontario: A Hedonic Approach. Master's Thesis, University of Guelph, Guelph, ON, Canada, 2017.

7. BMAPA (British Marine Aggregate Producers Association); The (England) Crown Estate; Defra, Marine Management Organisation; Natural England; JNCC; Historic England; Cefas. Good Practice Guidance: Extraction by Dredging of Aggregates from England's Seabed. 2017. Available online: https://bmapa.org/ documents/BMAPA_TCE_Good_Practice_Guidance_04.2017.pdf (accessed on 19 November 2019).

8. Nozahic, V.; Amziane, S.; Torrent, G.; Saïdi, K.; De Baynast, H. Design of green concrete made of plant-derived aggregates and a pumice-lime binder. Cem. Concr. Compos. 2012, 34, 231-241. [CrossRef]

9. Campbell, B.A. Aggregate Resource Extraction: Examining Environmental Impacts on Optimal Extraction and Reclamation Strategies. Master's Thesis, University of Alberta, Edmonton, AB, Canada, 2014. Available online: https://era.library.ualberta.ca/items/a562f94b-dbd1-4c77-b4e8-2c5b53f5ff17/view/f2d8eabe-5f45-468b9f3c-2791b66db455/Campbell_Brett_A_201409_MSc.pdf (accessed on 19 November 2019).

10. European Environment Agency. Effectiveness of Environmental Taxes and Charges for Managing Sand, Gravel and Rock Extraction in Selected EU Countries; EEA Report no 2; European Environment Agency: Copenhagen, Denmark, 2008; p. 64. Available online: https://www.eea.europa.eu/publications/eea_report_2008_2/file (accessed on 19 November 2019).

11. Langer, W.H.; Arbogast, B.F. Environmental impacts of mining natural aggregate. In Deposit and Geoenvironmental Models for Resource Exploitation and Environmental Security; Nato Science Partnership Subseries 2; Fabbri, A.G., Gaál, G., McCammon, R.B., Eds.; Springer: Dordrecht, Switzerland, 2002; Volume 80.

12. Danielsen, S.W.; Kuznetsova, E. Resource management and a best available concept for aggregate sustainability. In Sustainable Use of Traditional Geomaterials Construction Practice; Geological Society: London, UK, 2016; Volume 416, pp. 59-70. 
13. Na, H. Environmental Ethics and Sustainable Design: A Case Study on the Traditional Korean Residential Building Type: Han Oak. Master's Thesis, School of Engineering Technology, Eastern Michigan University, Ypsilanti, Michigan, 2013.

14. Gradinaru, C.M.; Babor, D.; Gradinaru, A.C. Poly-ethylene terephthalate waste recycling for environment protection and sustainable building activities. In Proceedings of the 17th Edition of National Technical-Scientific Conference, Modern Technologies for the 3rd Millenium, Oradea, Romania, 22-23 March 2018; pp. 285-290.

15. Gradinaru, C.M.; Barbuta, M.; Ciocan, V.; Antohie, E.; Babor, D. The effects of sodium silicate on corn cob aggregates and on the concrete obtained with these agricultural waste. IOP Conf. Ser. Mater. Sci. Eng. 2018, 399, 012021. [CrossRef]

16. Gradinaru, C.M.; Barbuta, M.; Ciocan, V.; Serbanoiu, A.A. A study on the effects of the cement and mineral aggregates replacement with waste materials. IOP Conf. Ser. Mater. Sci. Eng. 2018, 399, 012020. [CrossRef]

17. Gradinaru, C.M.; Barbuta, M.; Ciocan, V.; Serbanoiu, A.A.; Gradinaru, A.C. Health and environmental effects of heavy metals resulted from fly ash and cement obtaining and trials to reduce their pollutant concentration by a process of combining-exclusion. In Proceedings of the 17th International Multidisciplinary Scientific Geoconference SGEM 2017, Albena, Bulgaria, 29 June-5 July 2017; Volume 17, pp. 441-447.

18. Gradinaru, C.M.; Serbanoiu, A.A.; Serbanoiu, B.V. Concrete with thermal insulating properties-A double benefit in terms of money and environmental protection. Adv. Environ. Sci. 2018, 10, 56-61.

19. Gradinaru, C.M.; Serbanoiu, A.A.; Serbanoiu, B.V. Fibre reinforced concrete-A sustainable material in the context of building industry and environmental challenges. Adv. Environ. Sci. 2018, 10, 1-6.

20. Mercader Moyano, P.; Requena García de la Cruz, M.V.; Yajnes, M.E. Development of new eco-efficient cement-based construction materials and recycled fine aggregates and Eps from Cdw. Open Constr. Build. Technol. J. 2017, 11, 381-394. [CrossRef]

21. Mercader Moyano, P.; Yajnes, M.; Caruso, S. Experimental characterisation of a cement-based compound with recycled aggregates and Eps from rehabilitation work. Revista de la Construcción 2016, 15, 97-106. [CrossRef]

22. Muntean, R.; Cazacu, C.; Chitonu, G.C.; Galatanu, T. Lost shuttering for columns as possible applications of dispersely reinforced concrete with polypropylene fibers. IOP Conf. Ser. Mater. Sci. Eng. 2018, 399, 12040. [CrossRef]

23. Muntean, R.; Cazacu, C. Using PET (polyethylene terephthalate) waste for buildings. J. Appl. Eng. Sci. 2011, 1, 73-80.

24. Serbanoiu, A.A.; Barbuta, M.; Burlacu, A.; Gradinaru, C.M. Fly ash cement concrete with steel fibers-Comparative study. Environ. Eng. Manag. J. 2017, 16, 1123-1128.

25. Oancea, I.; Bujoreanu, C.; Budescu, M.; Benchea, M.; Gradinaru, C.M. Considerations on sound absorption coefficient of sustainable concrete with different waste replacements. J. Clean. Prod. 2018, 203, 301-312. [CrossRef]

26. Chabriac, P.A.; Gourdon, E.; Gle, P.; Fabbri, A.; Lenorman, H. Agricultural by-products for building insulation: Acoustical characterization and modelling to predict micro-structural parameters. Constr. Build. Mater. 2016, 112, 158-167. [CrossRef]

27. Chabannes, M.; Nozahic, V.; Amziane, S. Design and multi-physical properties of a new insulating concrete using sunflower stem aggregates and eco-friendly binders. Mater. Struct. 2015, 48, 1815-1829. [CrossRef]

28. Faustino, J.; Silva, E.; Pinto, J.; Soares, E.; Cunha, V.M.C.F.; Soares, S. Lightweight concrete masonry units based on processed granulate of corn cob as aggregate. Materiales de Construcción 2015, 65, e055.

29. Binici, H.; Eken, M.; Dolaz, M.; Aksogan, O.; Kara, M. An environmentally friendly thermal insulation material from sunflower stalk, textile waste and stubble fibres. Constr. Build. Mater. 2014, 51, 24-33. [CrossRef]

30. Pinto, J.; Cruz, D.; Paiva, A.; Pereira, S.; Tavares, P.; Fernandes, L.; Varum, H. Characterization of corn cob as a possible raw building material. Constr. Build. Mater. 2012, 34, 28-33. [CrossRef]

31. Amziane, S.; Sonebi, M. Overview on Biobased building material made with plant aggregate. RILEM Techn. Lett. 2016, 1, 31-38. [CrossRef]

32. Leff, B.; Ramankutty, N.; Foley, J.A. Geographic distribution of major crops across the world. Glob. Biogeochem. Cycles 2004, 18. [CrossRef]

33. Farias, R.D.; García, C.M.; Cotes Palomino, T.; Andreola, F.; Lancellotti, I.; Barbieri, L. Valorization of agro-industrial wastes in lightweight aggregates for agronomic use: Preliminary study. Environ. Eng. Manag. J. 2017, 16, 1691-1699. [CrossRef] 
34. Binici, H.; Zengin, H.; Zengin, G.; Kaplan, H.; Yucegok, F. Resistance to sodium sulphate attack of plain and blended cement containing corncob ash and ground granulated blast furnace slag. Sci. Res. Essays 2009, 4, 98-106.

35. Nkayem Njeumen, D.E.; Mbey, J.A.; Kenne Diffo, B.B.; Njopwouo, D. Preliminary study on the use of corn cob as pore forming agent in lightweight clay bricks: Physical and mechanical features. J. Build. Eng. 2016, 5, 254-259. [CrossRef]

36. Pinto, J.; Vieira, B.; Pereira, H.; Jacinto, C.; Vilela, P.; Paiva, A.; Pereira, S.; Cunha, V.M.C.F.; Varum, H. Corn cob lightweight concrete for non-structural applications. Constr. Build. Mater. 2012, 34, 346-351. [CrossRef]

37. Mati-Baouche, N.; De Baynast, H.; Lebert, A.; Sun, S.; Lopez-Mingo, C.J.S.; Leclaire, P.; Michaud, P. Mechanical, thermal and acoustical characterization of an insulating bio-based composite made from sunflower stalks particles and chitosan. Ind. Crop. Prod. 2014, 58, 244-250. [CrossRef]

38. Practice Code for Execution of Concrete Works, Reinforced Concrete and Prestressed Concrete. Part 1: Concrete Production; NE 012/1; National Institute of Research-Development in Constructions and the Economy of Constructions: Bucharest, Romania, 2007.

39. Testing Hardened Concrete, Part 5: Flexural Strength of Test Specimens; SR EN 12390-5; Standards Association of Romania: Bucharest, Romania, 2019.

40. Testing Fresh Concrete, Part 6: Density; SR EN 12350-6; Standards Association of Romania: Bucharest, Romania, 2019.

41. Testing Hardened Concrete, Part 6: Split Tensile Strength of Test Specimens; SR EN 12390-6; Standards Association of Romania: Bucharest, Romania, 2010.

42. Testing Hardened Concrete, Part 3: Compressive Strength of Test Specimens; SR EN 12390-3; Standards Association of Romania: Bucharest, Romania, 2019.

(C) 2020 by the authors. Licensee MDPI, Basel, Switzerland. This article is an open access article distributed under the terms and conditions of the Creative Commons Attribution (CC BY) license (http://creativecommons.org/licenses/by/4.0/). 